\title{
HER4 isoform CYT2 and its ligand NRG1III are expressed at high levels in human colorectal cancer
}

\author{
YAN GUO $^{1,2}$, ZHIHUI DUAN ${ }^{1,3}$, YITAO JIA $^{4}$, CHAOYING REN $^{4}$, JIAN LV $^{1}$, PENG GUO $^{5}$, \\ WUJIE ZHAO ${ }^{4}$, BIN WANG ${ }^{4}$, SUQIAO ZHANG ${ }^{4}$, YAXING $\mathrm{LI}^{4}$ and ZHONGXIN LI ${ }^{1}$ \\ ${ }^{1}$ Second Department of Surgery, The Fourth Hospital of Hebei Medical University, Shijiazhuang, Hebei 050035; \\ ${ }^{2}$ Fifth Department of Oncology, The First Hospital of Shijiazhuang, Shijiazhuang, Hebei 050011; \\ ${ }^{3}$ Department of Endoscopy, Xingtai General Hospital of Hebei Medical University, Xingtai, Hebei 054001; \\ ${ }^{4}$ Third Department of Oncology, Hebei General Hospital, Shijiazhuang, Hebei 050051; \\ ${ }^{5}$ Department of Orthopedics, The Fourth Hospital of Hebei Medical University, Shijiazhuang, Hebei 050035, P.R. China
}

Received June 8,2017; Accepted December 20, 2017

DOI: $10.3892 / \mathrm{ol} .2018 .8124$

\begin{abstract}
The present study aimed to evaluate the expression of human epidermal growth factor receptor (HER4) isoforms and their ligand neuregulin 1 (NRG1) isoforms in human primary colorectal cancer (CRC). The mRNA expression of HER4 isoforms JM-a, JM-b, CYT1 and CYT2, and their ligand isoforms NRG1 I, II and III in CRC tissues and adjacent normal tissues were quantified by reverse transcription-quantitative polymerase chain reaction analysis. Univariate analysis and logistic regression analysis were performed to analyze the association between HER4 and NRG1 expression and lymph node metastasis in CRC. The expression levels of CYT1 $(\mathrm{P}=0.002)$, CYT2 $(\mathrm{P}=0.002)$ and NRG1 type III $(\mathrm{P}<0.001)$ were significantly higher in the $\mathrm{CRC}$ tissues than in the adjacent normal tissues. The expression of CYT2 was correlated with tumor stage $(\mathrm{P}=0.018)$, lymph node status $(\mathrm{P}=0.015)$ and tumor-node-metastasis $(\mathrm{P}=0.038)$ in CRC. The expression of NRG1III was correlated with lymph node metastasis, and the expression of CYT2 was associated with the expression of NRG1III ( $\mathrm{r}=0.691, \mathrm{P}<0.01)$. The logistic regression analysis indicated that expression of CYT2 >50 was a risk factor for lymph node metastasis in CRC. In conclusion the expression levels of CYT1, CYT2 and NRG1III were upregulated in CRC. An expression of CYT-2 $>50$ was identified as a risk factor for lymph node metastasis in CRC. Therefore, CY-2 and NRG1III may be involved in the progression of CRC.
\end{abstract}

Correspondence to: Professor Zhongxin Li, Second Department of Surgery, The Fourth Hospital of Hebei Medical University, 169 Tianshan Road, Shijiazhuang, Hebei 050035, P.R. China E-mail: lizhongxin99@163.com

Key words: colorectal cancer, human epidermal growth factor receptor 4, CYT1, CYT2

\section{Introduction}

Colorectal cancer (CRC) is the third most common type of cancer in men and women, and the second leading cause of cancer-associated mortality in Western countries (1). At the time of diagnosis, synchronous metastases can be found in almost $20-25 \%$ of patients with CRC, and the majority of patients with stage III disease have a poor prognosis within 5 years of diagnosis. The mainstream drugs used for advanced CRC include 5-fluorouracil, capecitabine, oxaliplatin, irinotecan, vascular endothelial growth factor (VEGF) antibody and epidermal growth factor receptor (EGFR) antibody, which may be used as a single agent or in combination in the first or secondary line of therapy $(2,3)$. However, these therapies are limited in application due to their toxic and adverse effects. Further understanding of the pathogenesis of CRC may provide support for investigating novel drugs and individualized treatments for CRC (4).

Human epidermal growth factor receptor 4 (HER4/ErbB4) belongs to the EGFR family, a group of transmembrane receptor tyrosine kinases (RTKs). At least four HER4 variants (JM-a/CYT1, JM-a/CYT2, JM-b/CYT1 and JM-b/CYT2) can be generated by different HER4 mRNA splicing $(5,6)$. Therefore, seven different human EGF RTKs have been found to be expressed in various normal and malignant cells: HER1 (EGFR/ErbB1), HER2 (ErbB2/Neu), HER3 (ErbB3), and four HER4 isoforms (JM-a/CYT-1, JM-a/CYT-2, JM-b/CYT-1 and JM-b/CYT-2) (7). Agents targeting EGFR and/or HER2 have been approved for clinical use. In addition, the overexpression or mutation of HER3 is associated with malignant cell growth, contributing to enhanced tumor progression and poor patient outcomes (8). There are potentially oncogenic ERBB4 mutations in non-small cell lung cancer (9), and it has been reported that HER4 is overexpressed in human colon cancer and enhances cellular transformation (10). In addition, HER4 promotes breast cancer cell proliferation, mediates acquired resistance to ERBB2 inhibitors and may serve as a prognostic marker in patients with breast cancer (11-14). However, the role of HER4 in CRC remains to be fully elucidated. The alternative splicing of HER4 yields four major isoforms, which differ in 
the extracelluar juxtamembrane domain (JM-a, vs. JM-b) and cytoplasmic domain (CYT-1, vs. CYT-2). Failure to account for isoform-specific roles in previous studies may have led to controversial reports on the role of HER4 in cancer. Therefore, it is important to definitively determine the expression of HER4 isoforms in CRC.

Neuregulins (NRGs) are HER4 ligands, and comprise a large family of EGF-like signaling molecules involved in cell-cell communication during development and disease. NRG1 is a high-affinity ligand of HER4, which is classified into at least three subgroups (types I-III) with 30 isoforms as a result of splicing variants (15). NRG1 type I and type II are processed at the membrane by metalloproteinases ADAM17 and ADAM19, whereas the NRG1 type III contains a cysteine-rich domain, which binds to and activates HER3 and HER4 (16).

The aim of the present study was to evaluate the expression of HER4 isoforms and the isoforms of the ligand NRG1 in human CRC tissues, and to analyze the correlation between their expression and the clinicopathological parameters of patients with CRC.

\section{Materials and methods}

Patient selection and biopsy collection. A total of 76 fresh-frozen samples (38 cancer tissues and 38 paired adjacent normal tissues) were obtained from patients with CRC who were treated at the Second Department of Surgery, The Fourth Hospital of Hebei Medical University (Hebei, China) between November 2013 and August 2014. The surgery was performed on patients by the same surgeon, and the samples were collected during primary surgery prior to chemotherapy or radiation. The tissues were diagnosed as CRC preoperatively by endoscopic biopsy, and the normal tissues were $5 \mathrm{~cm}$ from the tumor edge. All patients had a pathological diagnosis and complete clinical data. The detailed clinical data, including gender, age, tumor size, tumor location, histological type, tumor differentiation, serum carcinoembryonic antigen (CEA) level, gene mutation, lymph node metastasis status, and tumor-node-metastasis (TNM) stage were collected from patient's medical records. Clinical staging was performed in accordance with the TNM staging system, formulated jointly by the American Joint Committee on Cancer and the Union for International Cancer Control (1). All experiments were approved by the Ethics Committee of The Fourth Hospital of Hebei Medical University. Written informed consent was obtained from each patient. The endpoints were the assessments of the association between the expression of HER4 and NRG1 with the clinicopathological parameters of patients with CRC.

Reverse transcription-quantitative polymerase chain reaction (RT-qPCR) analysis. Total RNA was isolated from the cryopreserved tissues using TRIzol (Takara Bio, Inc., Otsu, Japan). Total RNA $(5 \mu \mathrm{g})$ was used for the synthesis of cDNA using a reverse transcription kit. The isoform-specific primers for HER4 and NRG1 are listed in Table I. RT-qPCR analysis was performed in triplicate with $1 \mu \mathrm{g}$ cDNA and $2.5 \mu \mathrm{m}$ primers in $25 \mu 1$ buffer using SYBR Premix Ex Taq (Takara Bio, Inc.) on a Light Cycler 480 as follows: $94^{\circ} \mathrm{C}$ for $4 \mathrm{~min} ; 94^{\circ} \mathrm{C}$ for $30 \mathrm{sec}$, $56^{\circ} \mathrm{C}$ for $30 \mathrm{sec}\left(40\right.$ cycles), and $72^{\circ} \mathrm{C}$ for $30 \mathrm{sec}$. The mRNA expression level was normalized to $\beta$-actin and calculated using the $2^{-\triangle \Delta C q}$ method (17).
Table I. Primers used in the present study.

\begin{tabular}{lll}
\hline Gene & Direction & \multicolumn{1}{c}{ Primer sequence } \\
\hline CYT1 & Forward & 5'-GGATGAAGAGGATTTGGAAG-3' \\
& Reverse & 5'-TCCTGACATGGGGGTGTA-3' \\
CYT2 & Forward & 5'-GAATAGGAACCAGTTTGTATA \\
& & CCG-3' \\
& Reverse & 5'-ACAGCAGGAGTCATCAAAA \\
& & ATC-3' \\
JMa & Forward & 5'TAACGGTCCCACTAGTCA-3' \\
& Reverse & 5'-CATGTTGTGGTAAAGTGG-3' \\
JMb & Forward & 5'-ATAGGCTCAAGTATTGAAG-3' \\
& Reverse & 5'-CCATCAGGCCGATGC-3' \\
NRG1 I & Forward & 5'-AGGGCAAGAAGAAGGAGCG-3' \\
& Reverse & 5'-CCTTCAGTTGAGGCTGGCATA-3' \\
NRG1 II & Forward & 5'-CGCCTTCCGAGCCTCTTTC-3' \\
& Reverse & 5'-CCTTCTCCGCACATTTTACA \\
& & AGA-3' \\
NRG1 III & Forward & 5'-CCGGCCTCAAGTGGGTATT-3' \\
& Reverse & 5'-CCCAGTGGTGGATGTAGATGT \\
& & AGA-3' \\
3-actin & Forward & 5'-CGTGACATTAAGGAGAAGCTG-3' \\
& Reverse & 5'-CTAGAAGCATTTGCGGTGGAC-3' \\
& &
\end{tabular}

NRG, neuregulin 1.

Statistical analysis. The gene expression levels between the cancer and adjacent tissues were compared using the Wilcoxon rank sum test. Two groups of independent samples were compared using the Mann-Whitney test. Spearman's correlation method was used to analyze the correlation between HER4 isoforms and the clinicopathological data. To identify variables, which were independent predictors of $\mathrm{CRC}$, univariate analysis and logistic regression analysis with backward stepwise selection were employed. The data were processed using SPSS 22.0 software (IBM SPSS, Armonk, NY, USA). P<0.05 was considered to indicate a statistically significant difference.

\section{Results}

Expression of HER4 and NRG1 isoforms in CRC tissues and adjacent normal tissues. The mRNA levels of CYT1 $(\mathrm{P}=0.002)$, CYT2 $(\mathrm{P}=0.002$, and NRG1 type III $(\mathrm{P}<0.001)$ were significantly higher in the CRC tissues, compared with those in adjacent normal tissues $(\mathrm{P}<0.05$; Fig. 1A-C). No significant differences in the mRNA levels of JM-a, JM-b, NRG1 type I or NRG1 type II were found between the cancer tissues and the adjacent normal tissues.

Association between HER4 and NRG1 expression and clinicopathological parameters in CRC. Of the 38 patients with CRC, the expression of CYT1 was significantly associated with the depth of invasion $(\mathrm{P}=0.027)$ and TNM stage $(\mathrm{P}=0.033)$ in $\mathrm{CRC}$ (Fig. 2A and $\mathrm{B})$. The median expression of CYT1 in T2-3 CRC was lower, compared with that of T4 (0.62, vs. 5.24, $\mathrm{P}=0.027)$. The median expression of CYT1 in stage II CRC was increased significantly compared with that of stage I 

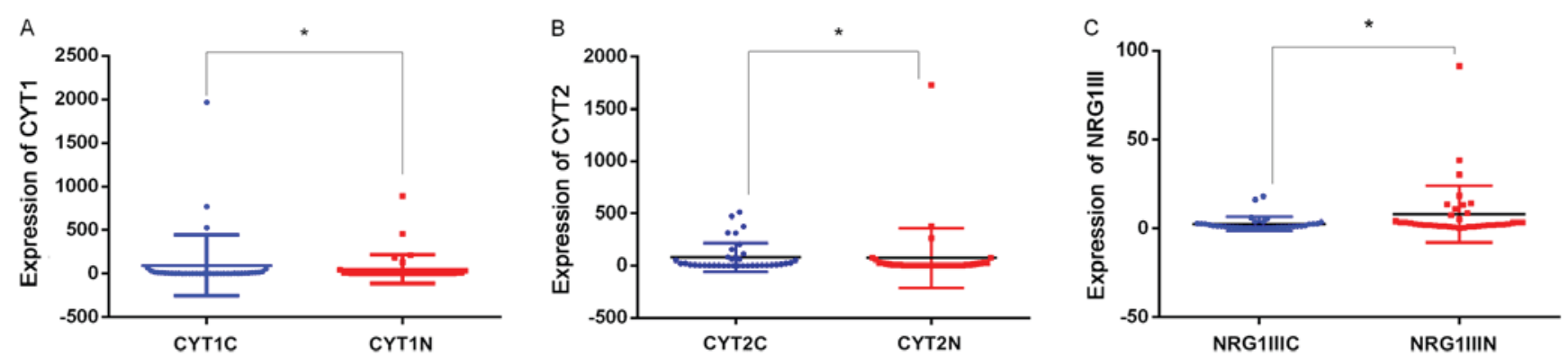

Figure 1. Expression levels of CYT1, CYT2 and NRG1 III. Comparison of the expression of (A) CYT1, (B) CYT2 and (C) NRG1 III between colorectal cancer tissues and adjacent normal tissues, determined by the Wilcoxon rank sum test. " $\mathrm{P}<0.05$. NRG1, neuregulin 1.
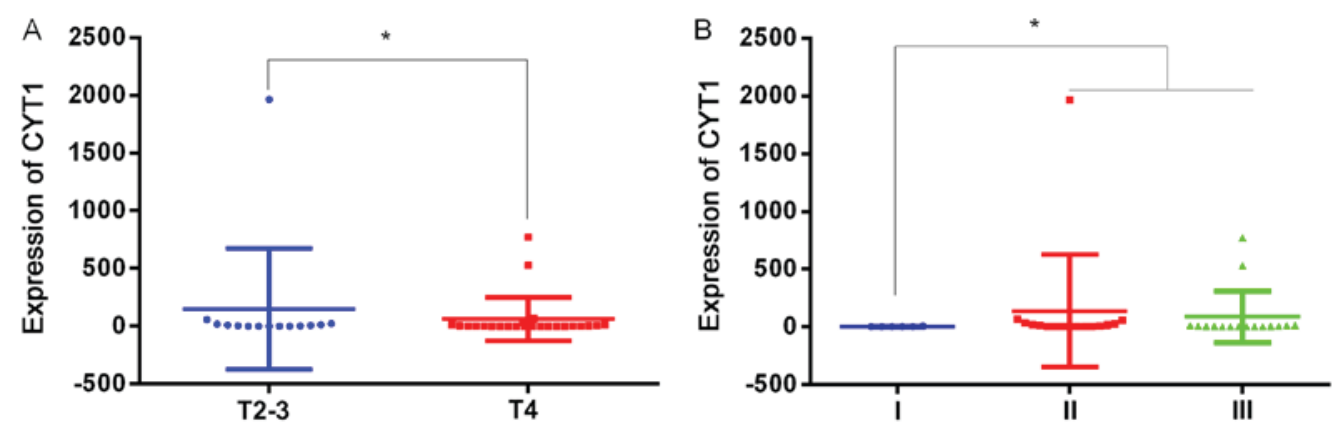

Figure 2. Association between CYT1 and clinicopathological variables. (A) Comparison of the expression of CYT1 between CRC at T2-3 and CRC at T4. (B) Comparison of the expression of CYT1 in CRC between different tumor-node-metastasis stages. ${ }^{\text {P }}<0.05$. The Wilcoxon rank sum test was used. CRC, colorectal cancer.
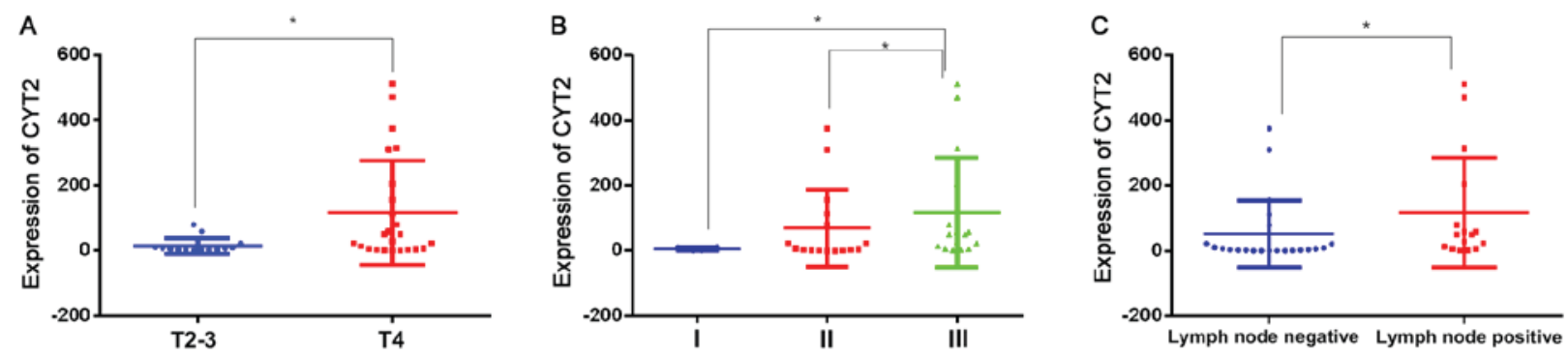

Figure 3. Association between CYT2 and clinicopathological variables. (A) Comparison of the expression of CYT2 between CRC at T2-3 and CRC at T4. (B) Comparison of the expression of CYT2 between CRC of different tumor-node-metastasis stages. (C) Comparison of the expression of CYT2 between CRC with positive lymph nodes and negative lymph nodes. ${ }^{*} \mathrm{P}<0.05$. The Wilcoxon rank sum test was used. CRC, colorectal cancer.

(0.42, vs. 10.25). However, there was no significant difference in the expression of CYT1 between stage II and stage III CRC.

The expression of CYT2 was associated with $\mathrm{T}(\mathrm{P}=0.018)$, $\mathrm{N}(\mathrm{P}=0.015)$, and TNM stage $(\mathrm{P}=0.038)$ in $\mathrm{CRC}$ (Fig. 3A-C). The median expression of CYT2 was increased significantly between T2-3 and T4 (5.36, vs. 39.48, respectively), and the expression was significantly increased in lymph node-positive cases, compared with that in lymph node-negative cases (5.36, vs. 50.59, $\mathrm{P}=0.015)$. The expression of CYT2 did not differ significantly between stages I and II, however, it was significantly higher in stage III (median=50.59), compared with that in stage I (median=5.9) and stage II (median =3.34; $\mathrm{P}<0.05)$.

The expression of NRG1 III was correlated with lymph node metastasis. The median expression was higher in the lymph node-positive cases than in the lymph node-negative cases ( 0.96 vs. $2.00 ; \mathrm{P}=0.015 ;$ Fig. 4 ). There was no correlation between

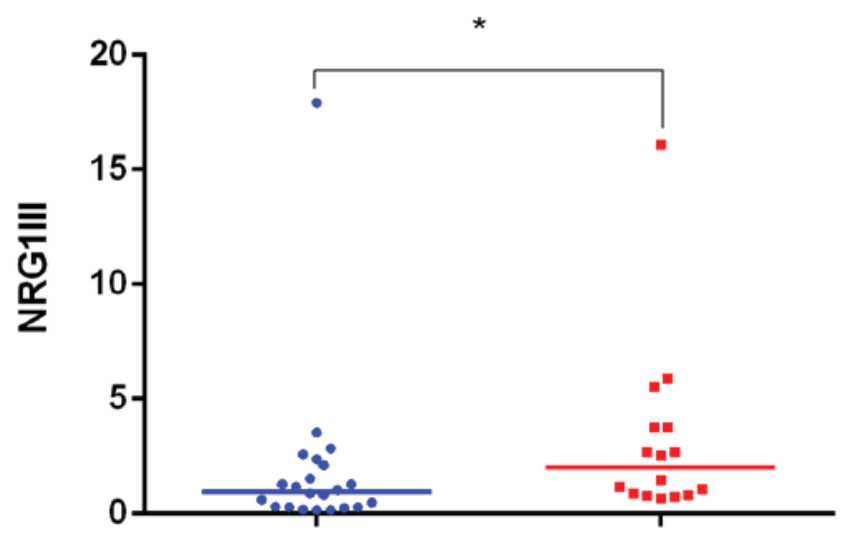

Lymph node negative Lymph node positive

Figure 4. Comparison of the expression of NRG1 III between colorectal cancer with positive and negative lymph nodes. ${ }^{\mathrm{P}} \mathrm{P}<0.05$. The Wilcoxon rank sum test was used. 
Table II. Association between human epidermal growth factor receptor 4 and NRG1 expression with clinicopathological parameters of colorectal cancer.

\begin{tabular}{|c|c|c|c|c|c|c|c|c|c|c|}
\hline \multirow[b]{2}{*}{ Variable } & \multirow[b]{2}{*}{$\mathrm{n}$} & \multicolumn{3}{|c|}{ CYT1 } & \multicolumn{3}{|c|}{ CYT2 } & \multicolumn{3}{|c|}{ NRG1 III } \\
\hline & & Median & IQP & P-value & Median & IQP & P-value & Median & IQP & P-value \\
\hline \multicolumn{11}{|c|}{ Age (years) } \\
\hline$\leq 62$ & 19 & 6.25 & 16.63 & \multirow[t]{2}{*}{0.15} & 13.95 & 76.93 & \multirow[t]{2}{*}{0.71} & 1.18 & 0.82 & \multirow[t]{2}{*}{0.77} \\
\hline$>62$ & 19 & 3.18 & 12.73 & & 10.33 & 56.71 & & 1.17 & 0.25 & \\
\hline \multicolumn{11}{|l|}{ Gender } \\
\hline Male & 23 & 3.60 & 13.25 & \multirow[t]{2}{*}{0.10} & 8.83 & 47.79 & \multirow[t]{2}{*}{0.39} & 1.17 & 0.76 & \multirow[t]{2}{*}{0.56} \\
\hline Female & 15 & 6.56 & 31.34 & & 50.59 & 154.29 & & 1.18 & 0.39 & \\
\hline \multicolumn{11}{|l|}{ Tumor size } \\
\hline$<4 \mathrm{~cm}$ & 17 & 4.92 & 14.12 & \multirow[t]{2}{*}{0.69} & 8.83 & 56.21 & \multirow[t]{2}{*}{0.73} & 1.27 & 0.89 & \multirow[t]{2}{*}{0.50} \\
\hline$>4 \mathrm{~cm}$ & 21 & 3.60 & 15.10 & & 13.95 & 132.45 & & 1.78 & 0.17 & \\
\hline \multicolumn{11}{|c|}{ Differentiation } \\
\hline High & 24 & 4.16 & 10.04 & \multirow[t]{2}{*}{0.32} & 18.11 & 7.040 & \multirow[t]{2}{*}{0.80} & 1.11 & 0.29 & \multirow[t]{2}{*}{0.73} \\
\hline Poor & 14 & 6.41 & 6.012 & & 5.26 & 192.93 & & 1.78 & 0.9 & \\
\hline \multicolumn{11}{|c|}{ TNM stage } \\
\hline I & 6 & 0.42 & 2.19 & \multirow[t]{3}{*}{$0.03^{\mathrm{a}}$} & 5.90 & 7.71 & \multirow[t]{3}{*}{$0.038^{\mathrm{a}}$} & 0.84 & 0.67 & \multirow[t]{3}{*}{0.08} \\
\hline II & 16 & 10.25 & 29.44 & & 5.34 & 102.96 & & 1.22 & 0.28 & \\
\hline III & 16 & 4.06 & 8.90 & & 50.59 & 166.36 & & 2.00 & 0.94 & \\
\hline \multicolumn{11}{|l|}{ T stage } \\
\hline $\mathrm{T} 2 / \mathrm{T} 3$ & 14 & 0.62 & 8.05 & \multirow[t]{2}{*}{$0.03^{\mathrm{a}}$} & 5.36 & 11.86 & \multirow[t]{2}{*}{$0.018^{\mathrm{a}}$} & 0.96 & 0.06 & \multirow[t]{2}{*}{0.20} \\
\hline $\mathrm{T} 4$ & 24 & 5.24 & 20.76 & & 39.48 & 189.12 & & 1.49 & 0.61 & \\
\hline \multicolumn{11}{|c|}{ Lymph node } \\
\hline Positive & 22 & 4.83 & 19.90 & 0.87 & 5.36 & 35.16 & $0.015^{\mathrm{a}}$ & 0.96 & 0.90 & $0.03^{\mathrm{a}}$ \\
\hline Negative & 16 & 4.06 & 8.90 & & 50.59 & 66.36 & & 2.00 & 0.94 & \\
\hline CEA & & & & & & & & & & \\
\hline Normal & 31 & 4.93 & 13.49 & 0.71 & 7.33 & 77.21 & 0.42 & 1.17 & 0.97 & 0.46 \\
\hline High & 7 & 4.73 & 14.72 & & 22.70 & 69.93 & & 1.52 & 0.11 & \\
\hline
\end{tabular}

t-test or one-way analysis of variance was used. ${ }^{\mathrm{a}}<<0.05$. NRG1, neuregulin 1 ; TNM, tumor-node-metastasis; CEA, carcinoembryonic antigen.

Table III. Correlation between the expression of human epidermal growth factor receptor 4 isoforms CYT1, CYT2 and NRG1 III.

\begin{tabular}{|c|c|c|c|c|c|c|}
\hline \multirow[b]{2}{*}{ Isoform } & \multicolumn{2}{|c|}{ CYT1 } & \multicolumn{2}{|c|}{ CYT2 } & \multicolumn{2}{|c|}{ NRG1III } \\
\hline & $\mathrm{r}$ & P-value & $\mathrm{r}$ & P-value & $\mathrm{r}$ & P-value \\
\hline CYT1 & - & - & 0.481 & $<0.05$ & 0.373 & $>0.05$ \\
\hline CYT2 & 0.481 & $<0.05$ & - & - & 0.691 & $<0.01$ \\
\hline NRG1III & 0.373 & $>0.05$ & 0.691 & $<0.01$ & - & - \\
\hline
\end{tabular}

Spearman's-Rho method was used. $\mathrm{P}<0.05$ indicates a statistically significant difference.

the expression of CYT-1, CYT-2 or NRG1 III with age, gender, tumor size, tumor grade and CEA levels ( $\mathrm{P}>0.05$, Table II).

Correlation analysis between the expression of CYT1 and CYT2 HER4 isoforms and NRF1 III. As shown in Table III, the expression of CYT1 and CYT-2 were associated ( $\mathrm{r}=0.481$,
$\mathrm{P}<0.05)$ and the expression of CYT2 and NRG1 were also associated $(r=0.691, P<0.01)$.

Analysis of variables associated with lymph node metastasis of CRC. As shown in Table IV, the univariate analysis showed that the expression of CYT2 was significantly 
Table IV. Univariate analysis and multivariate regression of variables associated with lymph node metastasis.

\begin{tabular}{|c|c|c|c|c|c|c|c|c|c|c|}
\hline \multirow[b]{3}{*}{ Variable } & \multicolumn{4}{|c|}{ Lymph node metastasis } & & & & & & \\
\hline & \multicolumn{2}{|c|}{ Yes } & \multicolumn{2}{|c|}{ No } & \multicolumn{2}{|c|}{ Univariate analysis } & \multicolumn{4}{|c|}{ Multivariate regression } \\
\hline & $\mathrm{n}$ & $\%$ & $\mathrm{n}$ & $\%$ & $\chi^{2}$ & P-value & OR & & $\% \mathrm{CI}$ & P-value \\
\hline \multicolumn{11}{|l|}{ Age (years) } \\
\hline$\leq 62$ & 9 & 56.2 & 10 & 45.5 & 0.432 & 0.372 & 0.124 & 0.009 & 1.732 & 0.121 \\
\hline$>62$ & 7 & 43.8 & 12 & 54.5 & & & & & & \\
\hline \multicolumn{11}{|l|}{ Gender } \\
\hline Male & 8 & 50 & 15 & 68.2 & 1.282 & 0.213 & 4.212 & 0.495 & 35.851 & 0.188 \\
\hline Female & 8 & 50 & 7 & 31.8 & & & & & & \\
\hline \multicolumn{11}{|c|}{ Differentiation } \\
\hline Poor & 11 & 68.8 & 13 & 59.1 & 0.371 & 0.369 & 3.826 & 0.417 & 35.109 & 0.235 \\
\hline High & 5 & 31.2 & 9 & 40.9 & & & & & & \\
\hline \multicolumn{11}{|l|}{ CEA } \\
\hline Normal & 13 & 81.2 & 18 & 81.8 & 0.002 & 0.641 & 2.428 & 0.066 & 89.515 & 0.630 \\
\hline High & 3 & 18.8 & 4 & 18.2 & & & & & & \\
\hline \multicolumn{11}{|l|}{ KRAS } \\
\hline Wild & 6 & 37.5 & 13 & 59.1 & 2.197 & 0.333 & 0.388 & 0.082 & 1.825 & 0.231 \\
\hline Mutation & 4 & 25 & 5 & 22.7 & & & & & & \\
\hline Indefinite & 6 & 37.5 & 4 & 18.2 & & & & & & \\
\hline \multicolumn{11}{|l|}{ Tumor size } \\
\hline$<4 \mathrm{~cm}$ & 6 & 37.5 & 11 & 50 & 0.585 & 0.521 & 9.183 & 0.302 & 279.614 & 0.203 \\
\hline$>4 \mathrm{~cm}$ & 10 & 62.5 & 11 & 50 & & & & & & \\
\hline \multicolumn{11}{|l|}{ CYT1 } \\
\hline$\leq 50$ & 14 & 87.5 & 19 & 86.4 & 0.10 & 0.654 & 0.001 & 0.001 & 1.821 & 0.071 \\
\hline$>50$ & 2 & 12.5 & 3 & 13.6 & & & & & & \\
\hline \multicolumn{11}{|l|}{ CYT2 } \\
\hline$\leq 50$ & 7 & 43.8 & 17 & 77.3 & 4.474 & $0.047^{\mathrm{a}}$ & 23.255 & 1.187 & 455.481 & $0.038^{\mathrm{a}}$ \\
\hline$>50$ & 9 & 56.3 & 5 & 22.7 & & & & & & \\
\hline \multicolumn{11}{|l|}{ NRG1I } \\
\hline$\leq 5$ & 15 & 93.8 & 21 & 95.5 & 0.054 & 0.671 & 0.470 & 0.002 & 105.457 & 0.785 \\
\hline$>5$ & 1 & 6.2 & 1 & 4.5 & & & & & & \\
\hline \multicolumn{11}{|l|}{ NRG1II } \\
\hline$\leq 5$ & 10 & 62.5 & 15 & 68.2 & 0.133 & 0.490 & 7.478 & 0.087 & 644.66 & 0.376 \\
\hline$>5$ & 6 & 37.5 & 7 & 31.8 & & & & & & \\
\hline \multicolumn{11}{|l|}{ NRG1III } \\
\hline$\leq 5$ & 13 & 81.3 & 21 & 95.5 & 1.984 & 0.192 & 5,292 & 0.236 & $1,186,341$ & 0.093 \\
\hline$>5$ & 3 & 18.8 & 1 & 4.5 & & & & & & \\
\hline \multicolumn{11}{|l|}{$\mathrm{JMa}$} \\
\hline$\leq 10$ & 12 & 75 & 19 & 86.4 & 0.796 & 0.317 & 0.274 & 0.001 & 52.022 & 0.628 \\
\hline$>10$ & 4 & 25 & 3 & 13.6 & & & & & & \\
\hline \multicolumn{11}{|l|}{$\mathrm{JMb}$} \\
\hline$\leq 10$ & 13 & 81.2 & 21 & 95.5 & 1.984 & 0.192 & 1.455 & 0.017 & 123.84 & 0.869 \\
\hline$>10$ & 3 & 18.8 & 1 & 4.5 & & & & & & \\
\hline
\end{tabular}

$\chi^{2}$ test was used. ${ }^{\mathrm{a}} \mathrm{P}<0.05$. NRG1, neuregulin 1 ; CEA, carcinoembryonic antigen.

associated with lymph node metastasis of CRC $(\mathrm{P}=0.047)$, whereas no significant associations were found between lymph node metastasis and age $(\mathrm{P}=0.372)$, gender $(\mathrm{P}=0.213)$, tumor differentiation $(\mathrm{P}=0.396)$, CEA level $(\mathrm{P}=0.641)$, KRAS mutation $(\mathrm{P}=0.333)$, tumor size $(\mathrm{P}=0.521)$, or the expression of CYT1 $(\mathrm{P}=0.654)$, NRG1I $(\mathrm{P}=0.671)$, NRG1II 
( $\mathrm{P}=0.490)$, NRG1III $(\mathrm{P}=0.192), \mathrm{JM}-\mathrm{a}(\mathrm{P}=0.317)$ or JM-b $(\mathrm{P}=0.192)$.

Logistic regression revealed that the expression of CYT2 was significantly associated with lymph node metastasis of CRC. In terms of the odds ratios (ORs), the variable of the expression of CYT2 had the most marked effect on lymph node metastasis; the OR of lymph node metastasis in cancer with CYT2 expression $>50$ was 23.255 times higher than that with CYT2 expression $\leq 50(\mathrm{P}=0.038$; Table IV).

\section{Discussion}

In the present study, it was demonstrated that HER4 isoforms CYT1 and CYT2, and their ligand NRG1 type III were upregulated in human CRC tissues. However, there was no significant difference in the expression of the other two HER4 isoforms (JM-a and JM-b) or the NRG1 type I and type II isoforms between CRC and normal tissues. The expression levels of CYT2 and CYT1 were closely associated with the TNM stage and tumor invasion depth of CRC, and the expression of CYT2 was associated with lymph node metastasis in CRC. However, only NRG1 type III was associated with lymph node metastasis in CRC.

In contrast to other members of the HER family, a single HER4 gene has four isoforms: JM-a, JM-b, CYT1 and CYT2, which are produced by alternative splicing. CYT1 and CYT2 differ by 16 amino acids present in the cytoplasmic tail of CYT1, which are not present in CYT2. This difference in the structure of CYT1 and CYT2 leads to their different cell location, resulting in different and even opposite roles in cell regulation. In the present study, it was found that the expression of CYT1 in CRC tissues was positively correlated with the depth of tumor invasion and TNM stage. Previous studies have indicated that CYT-1 is an independent prognostic factor of ovarian cancer, and that CYT-1 may promote the progression of ovarian cancer and malignant melanoma $(18,19)$. In malignant melanoma, the expression of CYT1 suggested a short progression-free survival rate (19). Another study revealed that ERBB4 CYT1 has a novel oncogenic role in breast cancer (20). The mechanism by which CYT1 promotes tumor progression may be through activating the phosphatidylinositol-3 kinase/Akt signaling pathway to induce tumor cells to evade apoptosis.

Compared with CYT1, the role of CYT2 in cancer, particularly in the colon, remains to be fully elucidated. In bladder cancer, the expression of JM-a/CYT2 and estrogen receptor may be indicative of improved prognosis of bladder cancer (21). A previous study found that the CYT2 variant, but not the CYT1 variant, protected EGFR from ligand-induced degradation by competing with EGFR for binding to a complex containing the E3 ubiquitin ligase $\mathrm{c}-\mathrm{Cbl}$ and the adaptor Grb2 (22). In addition, another study showed that the ErbB4 CYT2 isoform promoted the transition from colon adenoma to carcinoma following adenomatous polyposis coli loss (23). However, another study demonstrated that the CYT2 isoform had an inhibitory effect on cancer cell growth (24). These inconsistent results may be due to the different cell types and the different expression levels of HER family members. The specific mechanism by which CYT2 promotes the occurrence and development of $\mathrm{CRC}$ requires further investigation.

NRG1 is important in the tumor microenvironment. Bone marrow stromal cells, cancer-associated fibroblasts and cancer cells can secrete NRG1 (25). NRG1 can be secreted by endothelial cells through autocrine or paracrine mechanisms of angiogenesis in ischemic tissues, in order to meet the needs of the rapid growth of tumor (26). NRG1 can be divided into at least three subsets, namely NRG1I, NRG1II and NRG1III. The expression of these isoforms shows tissue specificity and have different biological roles. Among the three subtypes of NRG1, the present study found that only the expression of NRG1III was increased in CRC. In addition, it was found that the expression of CYT2 was positively correlated with the expression of NRG1III, and the two were associated with lymph node metastasis in CRC. Therefore, the NRG1 III/CYT2 pathway may be important in the invasion and lymph node metastasis of CRC. However, in the present study, only the mRNA expression levels of the NRG1 and CYT2 isoforms were detected by RT-qPCR analysis, and additional experiments are required to detect protein expression levels of NRG1 and CYT2 isoforms via western blot or immunohistochemical analyses to confirm the conclusions. This is a major limitation of the present study.

In conclusion, the study is the first, to the best of our knowledge, to demonstrate upregulation in the expression levels of CYT1, CYT2 and NRG1 III in CRC. It was also found that CYT-2 expression $>50$ is a risk factor for lymph node metastasis in CRC. Therefore, CY-2 and NRG1III may be involved in the progression of CRC.

\section{Acknowledgements}

This study was supported by the Natural Science Foundation of Hebei Province of China (grant no. H2016307010).

\section{Competing interests}

The authors declare that they have no competing interests.

\section{References}

1. Torre LA, Bray F, Siegel RL, Ferlay J, Lortet-Tieulent J and Jemal A: Global cancer statistics, 2012. CA Cancer J Clin 65: 87-108, 2015.

2. PanoiliaE, SchindlerE, Samantas E, Aravantinos G, Kalofonos HP, Christodoulou C, Patrinos GP, Friberg LE and Sivolapenko G: A pharmacokinetic binding model for bevacizumab and VEGF165 in colorectal cancer patients. Cancer Chemother Pharmacol 75: 791-803, 2015.

3. Santoro V, Jia R, Thompson H, Nijhuis A, Jeffery R, Kiakos K, Silver AR, Hartley JA and Hochhauser D: Role of reactive oxygen species in the abrogation of oxaliplatin activity by cetuximab in colorectal cancer. J Natl Cancer Inst 108: djv394, 2015.

4. Dawson H and Lugli A: Molecular and pathogenetic aspects of tumor budding in colorectal cancer. Front Med (Lausanne) 2: 11, 2015.

5. Roskoski R Jr: The ErbB/HER family of protein-tyrosine kinases and cancer. Pharmacol Res 79: 34-74, 2014.

6. Veikkolainen V, Vaparanta K, Halkilahti K, Iljin K, Sundvall M and Elenius K: Function of ERBB4 is determined by alternative splicing. Cell Cycle 10: 2647-2657, 2011.

7. Muraoka-Cook RS, Sandahl MA, Strunk KE, Miraglia LC, Husted C, Hunter DM, Elenius K, Chodosh LA and Earp HS III: ErbB 4 splice variants Cyt 1 and Cyt 2 differ by 16 amino acids and exert opposing effects on the mammary epithelium in vivo. Mol Cell Biol 29: 4935-4948, 2009.

8. Lédel F, Stenstedt K, Hallström M, Ragnhammar P and Edler D: HER3 expression in primary colorectal cancer including corresponding metastases in lymph node and liver. Acta Oncol 54: 480-486, 2015

9. Kurppa KJ, Denessiouk K, Johnson MS and Elenius K: Activating ERBB4 mutations in non-small cell lung cancer. Oncogene 35: 1283-1291, 2016. 
10. Williams CS, Bernard JK, Demory Beckler M, Almohazey D, Washington MK, Smith JJ and Frey MR: ERBB4 is over-expressed in human colon cancer and enhances cellular transformation. Carcinogenesis 36: 710-718, 2015.

11. Mohd Nafi SN, Generali D, Kramer-Marek G, Gijsen M, Strina C, Cappelletti M, Andreis D, Haider S, Li JL, Bridges E, et al: Nuclear HER4 mediates acquired resistance to trastuzumab and is associated with poor outcome in HER2 positive breast cancer. Oncotarget 5: 5934-5949, 2014.

12. Machleidt A, Buchholz S, Diermeier-Daucher S, Zeman F, Ortmann $\mathrm{O}$ and Brockhoff G: The prognostic value of Her4 receptor isoform expression in triple-negative and Her2 positive breast cancer patients. BMC Cancer 13: 437, 2013.

13. Kim JY, Jung HH, Do IG, Bae S, Lee SK, Kim SW, Lee JE, Nam SJ, Ahn JS, Park YH and Im YH: Prognostic value of ERBB4 expression in patients with triple negative breast cancer. BMC Cancer 16: 138, 2016.

14. Canfield K, Li J, Wilkins OM, Morrison MM, Ung M, Wells W, Williams CR, Liby KT, Vullhorst D, Buonanno A, et al: Receptor tyrosine kinase ERBB4 mediates acquired resistance to ERBB2 inhibitors in breast cancer cells. Cell Cycle 14: 648-655, 2015.

15. Zhao WJ: The expression and localization of neuregulin-1 (Nrg1) in the gastrointestinal system of the rhesus monkey. Folia Histochem Cytobiol 51: 38-44, 2013.

16. Papaleo F, Yang F, Paterson C, Palumbo S, Carr GV, Wang Y, Floyd K, Huang W, Thomas CJ, Chen J, et al: Behavioral, neurophysiological, and synaptic impairment in a transgenic neuregulin1 (NRG1-IV) murine schizophrenia model. J Neurosci 36: 4859-4875, 2016.

17. Livak KJ and Schmittgen TD: Analysis of relative gene expression data using real-time quantitative PCR and the 2(-Delta Delta C(T)) method. Methods 25: 402-408, 2001.

18. Paatero I, Lassus H, Junttila TT, Kaskinen M, Bützow R and Elenius K: CYT-1 isoform of ErbB4 is an independent prognostic factor in serous ovarian cancer and selectively promotes ovarian cancer cell growth in vitro. Gynecol Oncol 129: 179-187, 2013.
19. Nielsen TO, Poulsen SS, Journe F, Ghanem G and Sorensen BS: HER4 and its cytoplasmic isoforms are associated with progression-free survival of malignant melanoma. Melanoma Res 24: 88-91, 2014

20. Wali VB, Gilmore-Hebert M, Mamillapalli R, Haskins JW, Kurppa KJ, Elenius K, Booth CJ and Stern DF: Overexpression of ERBB4 JM-a CYT-1 and CYT-2 isoforms in transgenic mice reveals isoform-specific roles in mammary gland development and carcinogenesis. Breast Cancer Res 16: 501, 2014.

21. Munk M, Memon A, Poulsen SS, Borre M, Nexo E and Sorensen BS: The HER4 isoform JM-a/CYT2 relates to improved survival in bladder cancer patients but only if the estrogen receptor $\alpha$ is not expressed. Scand J Clin Lab Invest 73: 503-513, 2013.

22. Kiuchi T, Ortiz-Zapater E, Monypenny J, Matthews DR, Nguyen LK, Barbeau J, Coban O, Lawler K, Burford B, Rolfe DJ, et al: The ErbB4 CYT2 variant protects EGFR from ligand-induced degradation to enhance cancer cell motility. Sci Signal 7: ra78, 2014.

23. Bae JA, Kho DH, Sun EG, Ko YS, Yoon S, Lee KH, Ahn KY, Lee JH, Joo YE, Chung IJ, et al: Elevated Coexpression of KITENIN and the ErbB4 CYT-2 isoform promotes the transition from colon adenoma to carcinoma following APC loss. Clin Cancer Res 22: 1284-1294, 2016.

24. Nielsen TO, Sorensen S, Dagnæs-Hansen F, Kjems J and Sorensen BS: Directing HER4 mRNA expression towards the CYT2 isoform by antisense oligonucleotide decreases growth of breast cancer cells in vitro and in vivo. Br J Cancer 108: 2291-2298, 2013.

25. Han ME, Kim HJ, Shin DH, Hwang SH, Kang CD and Oh SO: Overexpression of NRG1 promotes progression of gastric cancer by regulating the self-renewal of cancer stem cells. J Gastroenterol 50: 645-656, 2015.

26. Park J, Sarode VR, Euhus D, Kittler R and Scherer PE: Neuregulin 1-HER axis as a key mediator of hyperglycemic memory effects in breast cancer. Proc Natl Acad Sci USA 109: 21058-21063, 2012. 